\title{
SCREW MICROMETER GAGES FOR RUBBER SPECIMENS
}

\author{
By W. L. Holt
}

ABSTRACT

Screw micrometers combined with an electrical contact indicating device have been adapted to measuring the dimensions of soft rubber parts. Three types of gages have been built. Two of these are vertical gages for thickness measurements and the other is a horizontal gage for dimensions, such as the width of test specimens and the diameter of cylindrical or spherical parts. Measurements made with the micrometer gages are compared with (1) the thickness or diameter computed from the volume and (2) those made with the usual type of dial gages. The micrometer gage measurements agree very closely with the computed values due to the precision of the micrometer screw and the fact that there is little compression of the rubber at points of contact.

\section{CONTENTS}

I. Introduction

II. Indentation of rubber by spherical contacts.

III. Description of gages

IV. Use of gages and precision of measurements

$\mathrm{V}$. Comparisons with other methods of measurement

VI. Summary

581

582

\section{INTRODUCTION}

The screw micrometer as a means of making precise measurements has advantages over many other types of measuring devices, due to simplicity of construction and the fact that it is inherently a highprecision instrument. In adapting it to measuring the dimensions of soft rubber specimens, however, the difficulty arises as to how to determine the point at which the spindle and anvil are in contact with the specimen or the amount of pressure that is being applied to the specimen. The compression of the material due to the applied pressure introduces an error in measurement which may or may not be significant.

In the present work, screw micrometers have been adapted to measurement of rubber parts by the use of electrical contacts, together with an indicating device as a means of determining when the gage foot touches the rubber specimen.

\section{INDENTATION OF RUBBER BY SPHERICAL CONTACTS}

Theoretically the thickness of a rubber sample is taken to be the distance between the spindle and the foot of the micrometer when each is just touching the sample. In the gages described the aim has been 
to use pressures as near zero as possible so that any compression of the sample at the contact with gage parts will be neglible. It is necessary, or at least convenient, to make one of the surfaces of the gage contacts spherical and the other plane, and accordingly, it is desirable to determine the indentations which spherical contacts produce for given loads. To obtain these data, a lever arrangement was used as shown in figure 1. Three lenses having radii of curvature of 0.7 inch, 1 inch, and 2 inches, respectively, were used for the spherical surfaces and two types of rubber - a pure gum and a tread stock were tested. The samples were of sufficient thickness so that the thickness did not influence the amount of indentation. Micrometer readings were taken at a series of loads between 0.02 and $2 \mathrm{~g}$. The measured thickness obtained with each lens was plotted against load for each rubber specimen. Each curve was extended back to the zero load axis to determine the micrometer reading at zero load. Using the micrometer readings at zero load, the actual indentations are readily determined. They are shown graphically in figure 2 .

Differences in indentation with the three lenses are small so that they can not be determined with precision by the method used.

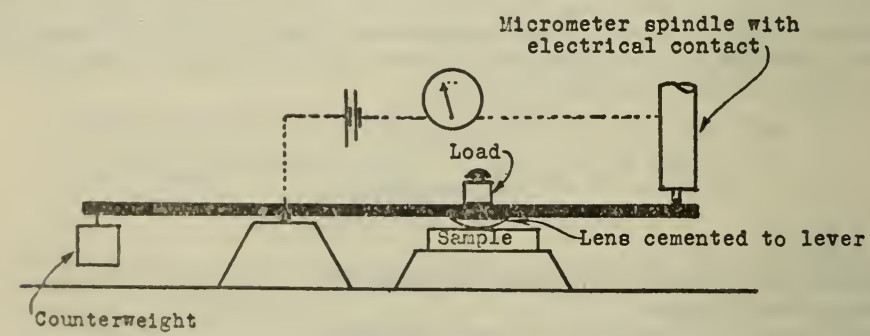

FIGURE 1.-Line drawing showing lever arrangement used for measuring indentation

As a whole, however, indentations are found under loads of $1 \mathrm{~g}$ (the lond subsequently chosen) from 0.0003 to 0.0005 inch for pure gum and from 0.0002 to 0.0003 inch for tread stock. These figures represent indentation errors which may occur under the most unfavorable conditions, but it will be evident from the data presented that the errors enter in different degrees depending upon the dimensions and type of sample measured and the gage used. Based on these indentation data, a radius of curvature of 1 inch was chosen for the spherical contact with a force of not more than $1 \mathrm{~g}$ to act upon it. The diameters of contacts in all cases were made sufficiently large so that in the softest rubber the diameter of the contact surface would be less than the diameter of the contact.

\section{DESCRIPTION OF GAGES}

Three types of gages were developed. Two of these are of the vertical type for making thickness measurements and the third, a horizontal gage for measuring diameters, widths, etc.

Figure 3 illustrates the single contact thickness gage. It consists essentially of a table with an arm spanning it and carrying at its center a standard micrometer head having a $1 / 4$-inch spindle. A on the under side of the table-the foot extending through the table 
and free to project about three one-thousandths of an inch above it. The contact surface of the presser foot is a portion of a sphere of 1 inch radius and is mounted at the end of a light spring. When it is pressed down until flush with table top an electrical contact is made which is indicated on the galvanometer. To accomplish this, a force slightly less than $1 \mathrm{~g}$ is required. The micrometer is mounted so that it reads zero when the spindle presses down the presser foot and causes electrical contact. Small adjustments which may be necessary due to temperature changes or other causes can be made by moving the index wheel on the spindle or by changing the position of the index guide.

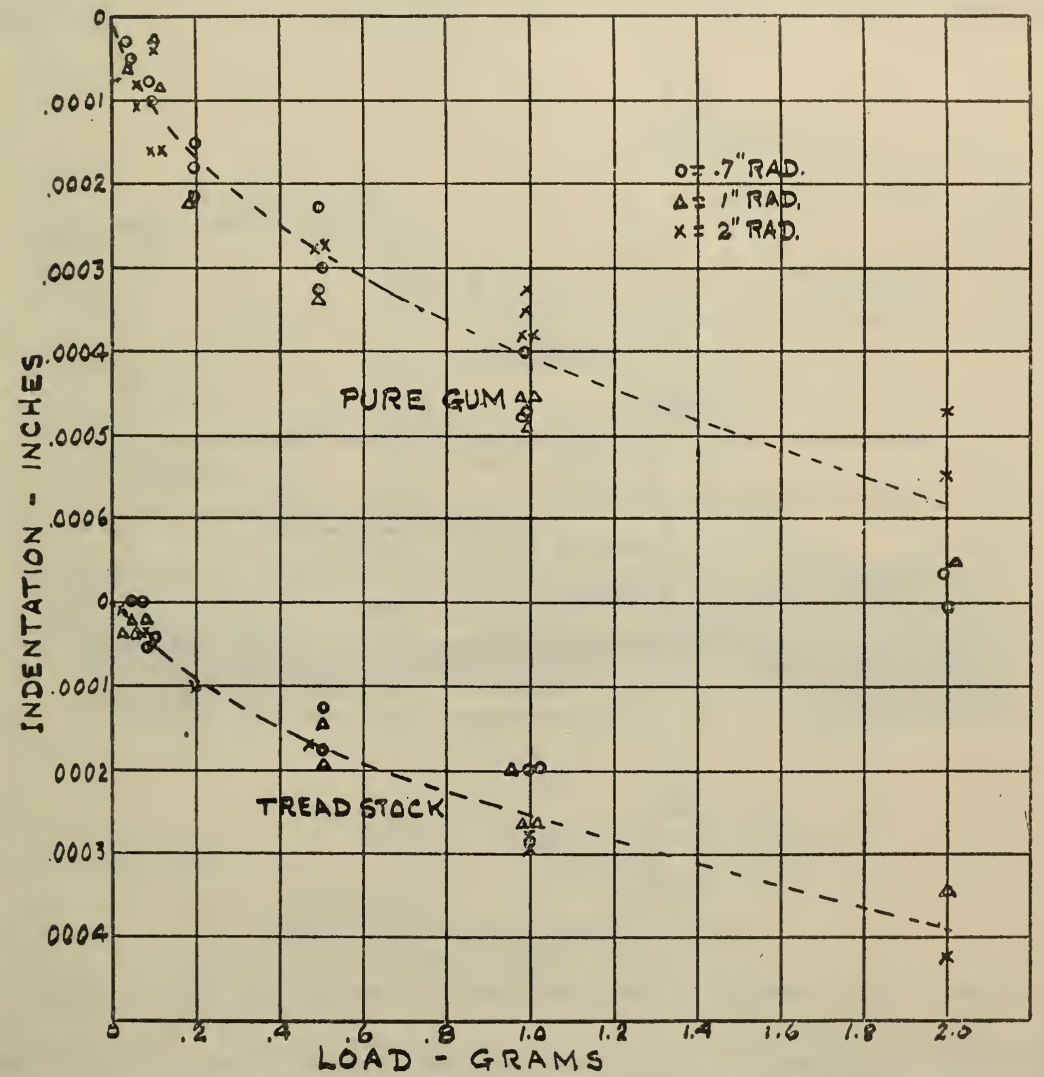

FiguRE 2.-Indentation of spherical surfaces in pure gum rubber and in tread stock.

Data are shown for lenses of 0.7 inch, 1 inch, and 2 inches radii, respectively.

Figure 4 illustrates the double contact thickness gage. The general construction is similar to the single contact gage except that a micrometer replaces the lower adjusting screw and electrical contacts and a spherical presser foot are added to the upper micrometer. The lower presser foot is the same as in the single contact gage while the upper one consists of an aluminum rod which is free to move vertically. Its weight is about $0.7 \mathrm{~g}$. Electrical contact is made by movement of the top of this rod which lifts a contact set in a narrow strip of copper foil. 
The thickness gages will accommodate specimens up to 1 inch thick.

Figure 5 illustrates the gage used for horizontal measurements. This operates on the same principle as the other gages. The main difference is in the table on which the specimen rests. This table is adjustable in height to permit alignment of the specimen with the micrometer. It has also been found better to adjust the presser foot to project about five one-thousandths of an inch at the time of electrical contact, rather than flush with the carrying arm. The table is slightly inclined so that specimens tend to roll or slip toward the flat micrometer spindle rather than toward the presser foot. The gage has been found useful in measuring the width of a test specimen

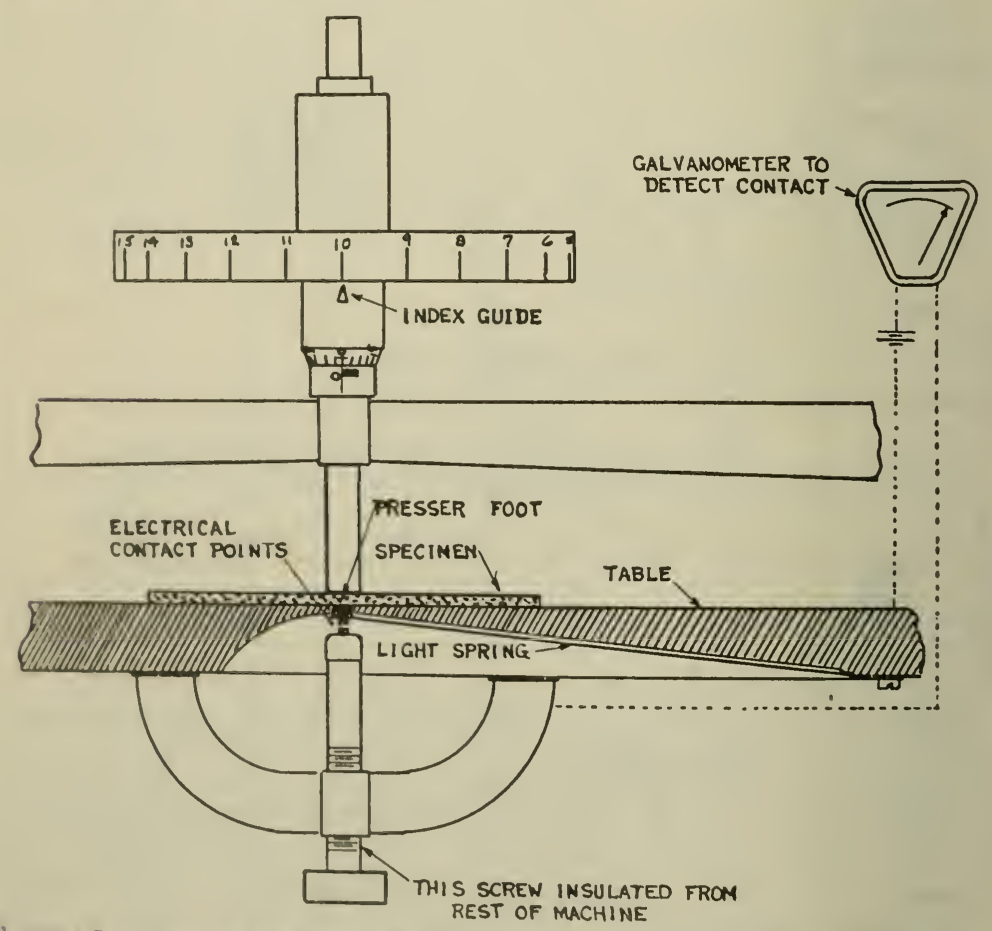

Fiсин: 3.-Line drawing showing arrangement of single contact thickness gage.

provided the section is approximately rectangular and not too thin. Measurements obviously cannot be depended upon where the cut surfaces are not plane and parallel. When the gage is used for width measurements, a small steel block 0.3 inch long is used, which slides in the central goove. 'Two positions for the arm carrying the contact 1 and 2 inches.

In making measurements with any of the gages the specimen is placed between the micrometer spindle and the presser foot (or is made. There feet) and the head or heads turned until contact the "make" or "break" "in the cifle diflence in measurements whether the most conver "make" seems With the double contact gage the difference 
between the two micrometer readings is the desired thickness while with the other gages the thickness is read directly. The index wheels permit convenient reading to 0.0001 inch.

The electrical contact points in all the gages are of platinum and the circuits such that the current is extremely small to insure perma-

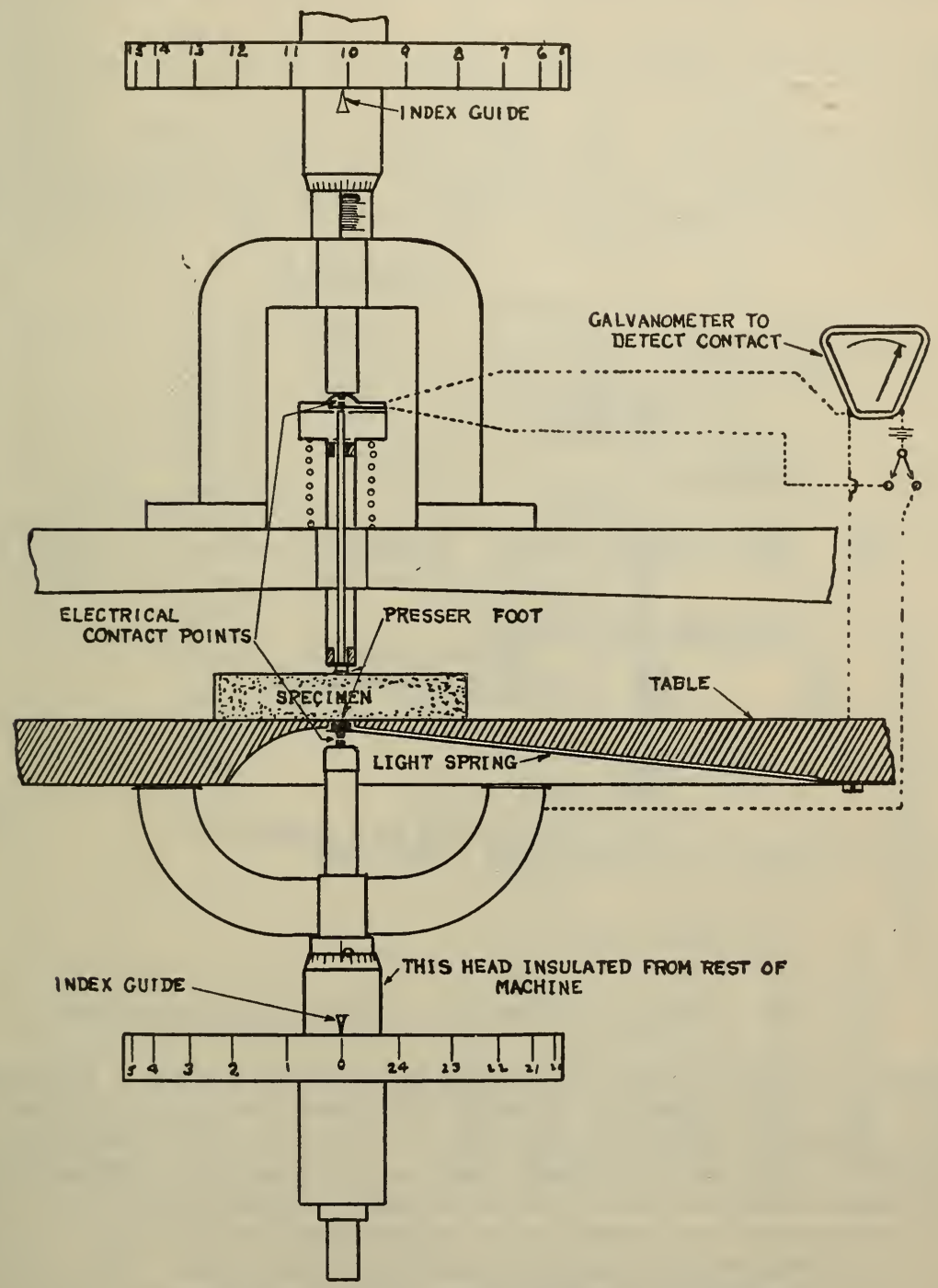

Figure 4.-Arrangement of double contact thickness gage.

nent contact points. In our work, one dry cell is used with a resistance of $5000 \mathrm{ohms}$ in the circuit and detection made with a sensitive millivoltmeter. The most practical instrument would be a low potential, low current, rugged null point galvanometer, together with a suitable resistance. In using the gages it is convenient to have the galvanometer mounted behind the gage table and 5 or 6 inches 
above it. The operator can then read the micrometer and at the same time observe movement of the galvanometer pointer.

\section{USE OF GAGES AND PRECISION OF MEASUREMENTS}

The single contact thickness gage is adapted for measuring the thickness of soft rubber sheets up to about three-eighths inch thick. When using this gage it would be logical to expect that if sufficient pressure is applied to the specimen by the micrometer spindle to produce a retraction of the presser foot a serious indentation error would be introduced. Actually for light contact pressures the thickness of material in pure compression under the micrometer contact surface is limited, and the same condition holds with regard to

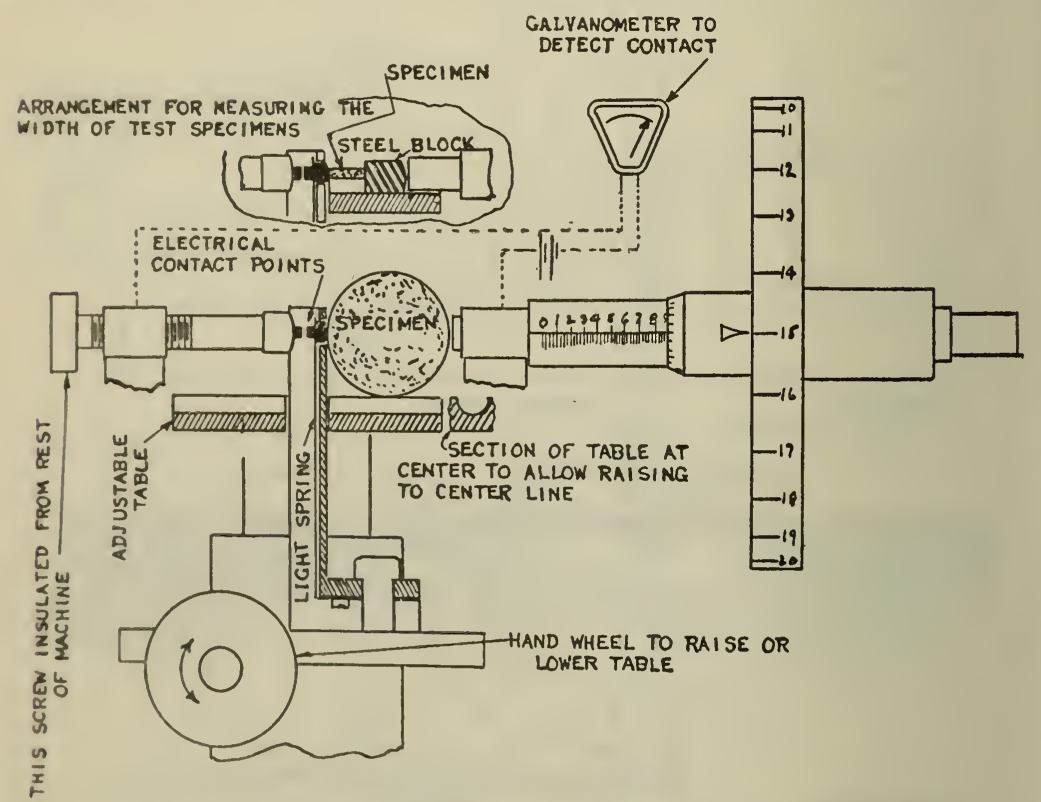

FIGURE 5.-Arrangement of gage for making horizontal measurements.

s layer of material above the presser foot contact surface. When the thickness of the specimen is such that these compression zones or layers interact directly, retraction of the presser foot results practically as soon as the spindle touches the specimen. With thick specimens it can be observed that in order to retract the presser foot the micrometer contact surface must be forced into the upper surface of the material and the thickness readings are too small. Accordingly for thick materials the double contact gage should be used. In practice it is found that very soft rubber sheets up to three-eighths inch thick can be measured with the single contact gage, although errors due to indentation of the micrometer spindle begin to become apparent at this thickness. The rccuracy of measurement with the single contact grage within the $1 / 4$-inch range is about 0.0002 inch. At threeeighths inch the recurncy is slightly less. With the double contact gare, which employs two spherical contact surfaces instead of a spherical and a flat surface, indentation errors such as are shown by 
figure 2 become evident and measurement of soft stocks may be as much as 0.0008 inch in error due to the two presser feet.

With the horizontal gage, indentation errors due to the one presser foot may amount to 0.0004 inch in soft stocks. Data given later indicate measurements of the diameter of soft rubber rods within this limit.

\section{COMPARISON WITH OTHER METHODS OF TESTING}

Table 1 shows measurements made with the micrometer gages compared with (1) those made with the usual type of dial gages and (2) thicknesses or diameters computed from volumes. The latter dimensions for rectangular sheets were obtained as follows: Test specimens from 4 to 6 inches square of different rubber compounds and of various thicknesses were molded or cut. Care was taken to make them with true edges so that the length and width could be measured with a precision of about 0.002 inch. The volume of each sheet was determined by hydrostatic weighings and the average thickness computed as the quotient of the volume and area. The average diameters of two rubber rods were also computed similarly from volume and length. Because of the high coefficient of thermal expansion of rubber, care was taken to make all volume determinations and linear measurements at the same temperature. This was particularly necessary for the thick samples.

TABLE 1.-Dimensions of rubber test specimens determined in different ways

THICKNESS OF RUBBER SHEETS

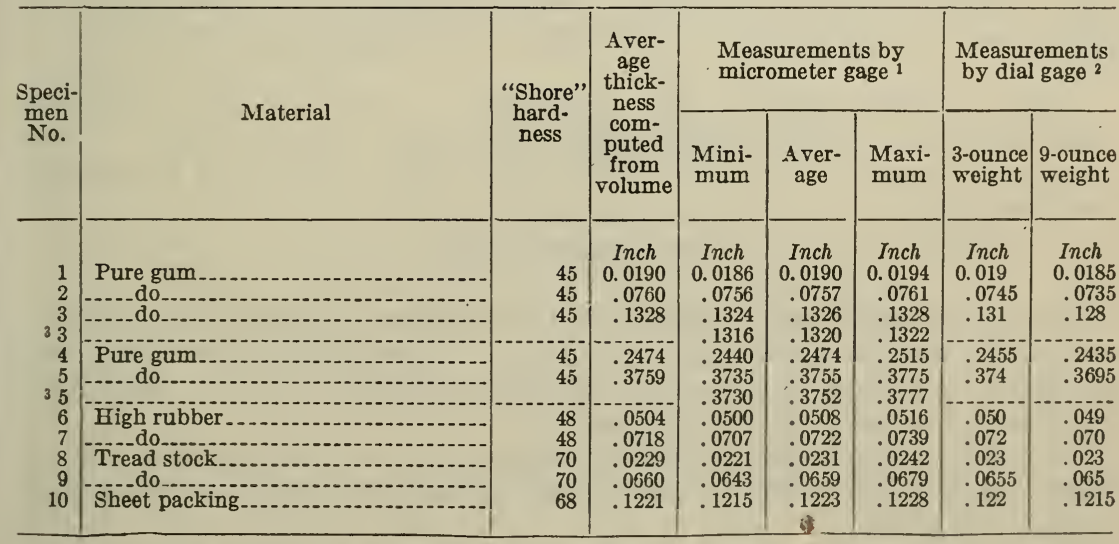

DIAMETER OF RUBBER RODS 4

\begin{tabular}{|c|c|c|c|c|c|c|c|c|}
\hline $\begin{array}{l}11 \\
12\end{array}$ & Pure gum & $\begin{array}{l}45 \\
45\end{array}$ & $\begin{array}{l}.6102 \\
.9792\end{array}$ & $\begin{array}{l}.6078 \\
.9764\end{array}$ & $\begin{array}{l}.6101 \\
.9788\end{array}$ & .6128 & & 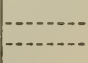 \\
\hline
\end{tabular}

1 Minimum, maximum, and average of at least 16 measurements.

2 Average measurements at the same points (corrected by calibration).

3 Measured with double contact gage.

4 Minum, maximum, and average of 18 measurements.

Measurements with each gage were made at the same 16 or more points distributed over a sample and the results averaged. The dial gage used was of standard design graduated to read to 0.001 inch. 
In each measurement the ten-thousandths place was estimated. $A$ complete calibration was then made of the dial gage and a correction made for each measurement. These corrections were erratic throughout the range of the instrument, varying from +0.0002 to -0.0006 inch. Average measurements are recorded in the table to the nearest 0.0005 inch.

Specimens nos. 1 to 5 are a series of pure gum sheets of increasing thicknesses and represent the most difficult type of rubber to measure without compression. Up to sample no. 5 the measured thicknesses of samples using the single contact gage do not differ from the computed values by more than 0.0003 inch. No. 5, which is three-eighths inch thick, begins to show the effect of compression of the spindle and indicates the practical limit of use for a gage of this design. Measurements of specimens 3 and 5 made with the double contact gage are shown for comparison. Although the latter specimen can apparently be measured quite satisfactorily with either gage, it is found that the single contact gage is apt to give erroneous results if this limit is exceeded. The thinnest specimen (no. 1) shows very little indication of compression with any gage-all measured thicknesses being practically the same as the computed value. The thicker specimens all show decreases in indicated thickness as one goes from the micrometer gage to the 3 -ounce dial reading and to the 9 -ounce dial reading.

One would expect the micrometer gage thicknesses to be equal to or slightly less than the computed values, which condition appears to exist for the specimens most uniform in thickness. The fact that the gage measurements are slightly greater than the computed values in some cases is attributed to slight irregularities in the thickness or in the surface of the specimens which tend to make the measured distance high.

With the soft rubber rods, specimens 11 and 12 , the measured diameters are within 0.0001 and 0.0004 inch, respectively, of the computed values. No suitable dial gage was available for measuring the diameters.

\section{SUMMARY}

The micrometer gages described are adapted to measuring samples covering a wide range of sizes and shapes. These include the thickness of sheets up to 1 inch, the width of test specimens, and the diameters of rods and spheres up to 2 inches.

The gages eliminate or reduce errors due to compression of the rubber at points of contact, and for this reason are particularly adapted to soft compounds.

The advantage of the micrometer gages lies in accuracy of measurement due to the design of gages and the inherent precision of the micrometer screw.

Washington, February 16, 1933. 